\title{
El Centenario interminable Contenidos ideológicos y culturales del IV y V Centenario de 1492
}

\section{SALVADOR BERNABEU AlberT}

Los centenarios nacieron con una finalidad docente y progresista. Sus manifiestos y espectáculos, al igual que los que acompañaron a las exposiciones universales, el otro gran invento de la centuria decimonónica, se convirtieron en una de las tribunas culturales más importantes del siglo XIX. Sin embargo, el uso y el abuso de los mismos por parte de los poderes políticos para cimentar contemporáneas actitudes y empresas, los han convertido en blanco de numerosos ataques por parte de sectores cada día más crecientes de la sociedad. Pero cabría preguntarse si son obsoletos los centenarios o los contenidos que conmemoran. Lo que no hay duda es que a lo largo de 1992 la palabra centenario sufrirá un importante desgaste como jamás se habría pensado. Nacidos como gestas progresistas, son hoy un símbolo conservador; surgidos como serios movimientos pedagógicos, son hoy un campo de confusión y batalla.

Todo centenario nace de una perspectiva histórica. Parte de un pasado que es entregado - impuesto - a una generación, la cual, desde su presente, trata de reconstruirlo, juzgarlo, comprenderlo o simplemente negarlo. Por lo general actúa como una sacudida en el espíritu de un pueblo o de una colectividad para recuperar ciertas páginas notables de su pasado. Por eso, paralelamente, se genera la comparación del momento conmemorado con el conmemorador, naciendo una perspectiva política. En consecuencia, los aspectos culturales e ideológicos están íntimamente unidos con los políticos y socioeconómicos. En todo Centenario, que actúa como presente inmediato, el pasado y el futuro se dan la mano.

El pensamiento positivista decimonónico concibió la idea de elaborar un calendario que, a imagen del religioso, honrase cada día de cada mes a un bienhechor de la humanidad. No es extraño, por tanto, que en el siglo XIX se generalizase una práctica, ininterrumpida hasta hoy, consistente en conmemorar hombres o acontecimientos de gran trascendencia para una colectividad. El científico Felipe Picatoste escribió en 1892 que

Nuestro siglo, que no quiere pecar de ingrato con nuestros predecesores y ha hecho, o intentado hacer, la Historia del progreso humano en sus múltiples manifestaciones, ha introducido en las costumbres públicas la de los centenarios como justo tributo de 
admiración o de gratitud a los grandes hombres y a los sucesores que influyeron poderosamente en la historia general del mundo o en la particular de algún pueblo.'

La mayoría de la población conocía 'al dedillo' las vidas y milagros de beatos y santos, mientras inventores, científicos y pensadores, heterodoxos o no, eran víctimas de la más absoluta ignorancia. Pero lo que ocurrió fue que los centenarios pronto imitaron las ceremonias y prácticas religiosas: las procesiones eso sí, cívicas -, los lugares de peregrinaje, las grandes concentraciones frente al altar de los descubridores, poetas o pintores, las medallas, las inevitables estampitas y los libros y camisetas con rótulos obsesivos: „500 años de...", „350 años de...", „75 años de...".

Las conmemoraciones centenarias se iniciaron en España en 1876 con la dedicada al padre Feijoo. A ella le seguirían las de Calderón, Murillo, Santa Teresa, Saavedra Fajardo, San Juan de la Cruz, y de Álvaro de Bazán, primer marqués de Santa Cruz. Pero ninguno de estos centenarios tuvo la importancia y trascendencia del dedicado al Descubrimiento de América el año 1892. Su carácter mundial tuvo su expresión más significativa en un torneo honorífico entre España, Italia y los Estados Unidos, mientras que la participación de toda la sociedad española lo convierten en un espejo de la España decimonónica y una cala en el pensamiento finisecular. Anteriormente hubo conmemoradores, pero no conmemoración. ${ }^{2}$

\section{El Centenario de Colón}

Durante gran parte del siglo XIX, la idea del Descubrimiento de América estuvo ligada a la vida del gran Almirante. Esta confusión entre hecho y protagonista no fue genuina del siglo XIX, sino que gozó de amplia aceptación durante el siglo XVIII, e incluso a lo largo del Siglo de Oro. Con el trascurso de los años, la personalidad de Cristóbal Colón se fue enriqueciendo con las más nobles y elevadas virtudes: heroísmo, religiosidad, intrepidez, instinto, ingenio, perseverancia, caridad, etcétera. Cualidades que adquirió el gran Almirante gracias a las numerosas penalidades que tuvo que soportar durante su vida en Castilla. El Romanticismo retomó esta visión heroica colombina y la llevó hasta sus últimas consecuencias, si bien pronto surgieron dos variantes: la leyenda

Felipe Picatoste: „Influencia científica del descubrimiento de América“, en: El Centenario, vol. I, Madrid 1892, p. 349.

2 Salvador Bernabeu Albert: „El IV Centenario del Descubrimiento de América en la coyuntura finisecular (1880-1893)“, en: Revista de Indias, vol. XLIV, n 174 (1984), pp. 345-366; (id.): 1892. El IV Centenario del Descubrimiento de América en España: coyuntura y conmemoraciones, Madrid: CSIC 1987. mística y la leyenda idealista, a la que se uniría, al finalizar el siglo, la leyenda adversa o negativa como contrapartida.

Por otra parte, hay que señalar que la historiografía romántica, obsesivamente preocupada con los temas medievales, no fue muy generosa con los hechos acaecidos durante la Edad Moderna, a pesar de que en los primeros cronistas de Indias podían encontrarse tantos caballeros y dragones como en los más famosos relatos medievales. El tema del Descubrimiento de América tuvo muy poca fortuna entre los escritores románticos españoles, si bien no faltaron algunos ejemplos, como la novela histórica de Ignacio Miguel Pusalgas y Guerris (1790-1884): El sacerdote blanco o la familia de uno de los últimos caciques de la Isla de Cuba. Novela histórica americana del siglo decimo quinto. ${ }^{3}$ Novela que describe los amores de Valentín, marinero de Colón, con Pezinka, hija del cacique Koaapa, olvidándose de su prometida Elvira, quien se suicida al enterarse de los desdenes de su amado. Valentín resultará ser Hernando Colón y, al final de esta dramática historia, tanto el hijo de Cristóbal Colón como la bella india deciden tomar los hábitos religiosos.

Otros ejemplos de novelas románticas de tema colombino son: Cristóbal Colón. Historia popular (1858), de Francisco José Orellana, y Vida y Viajes de Cristóbal Colón (1874), de Ramón Ortega y Frías. Pero hasta la década de los ochenta, la novela histórica americana estuvo inspirada más en las hazañas y amores de los conquistadores, especialmente del extremeño Hernán Cortés, que en la azarosa vida del Almirante de la Mar Océana. ${ }^{4}$ Sin embargo, la proximidad del IV Centenario propició la aparición de una concurrida biblioteca colombina, que se nutrió tanto de los escritores locales como foráneos, especialmente franceses e italianos. De este modo fueron llegando a España otras variantes de la leyenda colombina.

Roselly de Lorgues, conde por concesión romana, fue el inspirador de esta leyenda. En su juventud había publicado varias obras del más exaltado misticismo, como Le Christ devant le siècle, ou Nouveaux témoignages des sciences en faveur du catholicisme (1835), y De la Mort avant l'homme et du péché originel (1841). Pero no fue hasta la publicación de La Croix dans les deux mondes, ou la Clef de la connaissance (1845) cuando inició la batalla por la santidad de Colón, que sería ampliamente comentada y reivindicada en su más famosa obra: Christophe Colomb, histoire de sa vie et de ses voyages d'après des documents authen-

Publicada en Barcelona: Imp. Ramón M. Indar 1839, 2 vols.

Salvador Bernabeu Albert: „Hernán Cortés en el siglo XIX. Proceso al conquistador“, en: Actas del Congreso 'Hernán Cortés y su tiempo', 2 vols., Junta de Extremadura, Editorial Regional Extremeña 1987; vol. I, pp. 421-425. 
tiques tirés d'Espagne et d'Italie (1856), obra ricamente ilustrada que obtuvo gran éxito en todos los países católicos europeos. Para Roselly de Lorgues, Cristóbal Colón fue auxiliado por la Santa Sede y el clero católico en su magna empresa, teniendo su viaje como única meta la propagación del Evangelio y la conversión de los americanos.

En torno suyo se creó un poderoso e influyente grupo formado tanto por seglares - por ejemplo Léon Bloy, autor de Le Révélateur du globe. Christophe Colomb et sa béatification future (1884) - como por religiosos, entre los que cabe resaltar al arzobispo de Burdeos, cardenal Donnet, y ¡como no! al arzobispo de Génova, monseñor Andrea Charvaz, quienes apoyaron la causa de santificación de Colón. Primero en 1866, y más tarde durante la celebración del I Concilio Vaticano, fueron presentadas las peticiones correspondientes a la Congregación de Ritos, aunque finalmente no prosperó ninguna (resolución negativa de octubre de 1877). No por ello se desanimaron los partidarios del gran Almirante. Roselly de Lorgues siguió con su labor propagandística, mientras Giuseppe di G. Baldi, autor de La glorificazione del genio cristiano [...] (1879), entregó al papa León XIII un álbum con 466 adhesiones episcopales, que aumentaron en 1885 a 627.

Los postulados de Roselly - 'San Cristóbal Colón' - tuvieron en España una amplia repercusión. Sirvan, a modo de ejemplos, las siguientes obras: Colón. Poema Histórico (1887), poema ilustrado de Bernabé Demaría; el Discurso sobre la influencia del Espíritu cristiano en el ánimo de Cristóbal Colón para la realización de su empresa (1893), de Francisco Rubio Contreras; y Cristóbal Colón. El héroe del catolicismo (1885), de Baldomero Lorenzo y Leal. Coincidiendo con el IV Centenario, se tradujo la obra de Michel Angelo Maria Mizzi Cristóbal Colón, misionero-navegante y apóstol de la Fe. Apuntes históricos (1892), con cuyos postulados comulgó la gran mayoría de la Iglesia española, aunque no faltaron ciertas voces disidentes, como la del padre Coll, quien escribió en su obra Colón y La Rábida:

¡Mucho! ¡Como si en la corte pontificia se comulgara con ruedas de molino! [...] Sábese muy bien en aquella metrópoli del catolicismo, mejor quizá que en España, que la semblanza de aquel héroe tiene dos aspectos: como descubridor no tiene par, y en este concepto podemos decir que se ajusta bien a su talla, todas le vienen cortas; pero en calidad de virrey, como por lo visto no le tenía Dios destinado para gobernar

5 Las nuevas obras de Roselly de Lorgues fueron: Satan contre Christophe Colomb, ou la Prétendue chute du serviteur de Dieu, Paris 1876; Les Deux cercueils de Christophe Colomb, Paris 1882; Christophe Colomb, Serviteur de Dieu. Son Apostolat, sa Sainteté, Paris 1884; Histoire posthume de Christophe Colomb, Paris 1885. dilatados reinos, no siempre mereció plácemes y loores, ¡ay! no. Esto consta perfectamente en Roma, y ello es muy bastante para que no se dé un paso en lo tocante a la soñada beatificación.

Conforman la leyenda idealista una larga lista de obras, principalmente poemas o biografías novelescas, de acuñación romántica, que recrearon a finales del siglo XIX, y aún en el XX, una visión de Colón heroica y caballeresca sin escatimar los más variados y fantásticos episodios en aras de sorprender al lector y de dotar al gran navegante genovés de todos los atributos de los modernos protagonistas de los filmes de aventuras. Como cabe suponer, las inexactitudes históricas fueron incontables y las invenciones de gran audacia. Las obras más importantes de las que se hicieron nuevas ediciones en Madrid en 1892 fueron: Historia del descubrimiento y conquista de América, del alemán J.E. Campe; Biografia de Cristóbal Colón, del francés Lamartine; y História de la vida y viages de Cristóbal Colón, del norteamericano Washington Irving. ${ }^{7}$ Esta última fue considerada la mejor biografía de Colón durante gran parte del siglo XIX. La base documental de esta leyenda fue, según el sabio español Marcelino Menéndez y Pelayo, la Historia del Almirante de Hernando Colón:

Con este libro comenzó a formarse lo que ahora llaman la leyenda colombina y por eso es el principal baluarte de los que la defienden, así como el principal blanco de los tiros de los que la atacan. Notorio es, sin embargo, que la tal leyenda ha sido pródigamente enriquecida por la imaginación de los panegiristas posteriores, y así no hay rastros, por ejemplo en el libro de don Fernando, del supuesto matrimonio clandestino del Almirante con Beatriz Enríquez $[\ldots]^{8}$

La leyenda romántica-idealista del navegante genovés contó con gran popularidad gracias a su constante difusión en folletos, libros ilustrados de gran lujo y novelas por entregas. Pero al acercarse 1892, un importante grupo de historiadores y escritores ibéricos se propusieron desnudar a Colón de toda leyenda y darle realidad histórica. Así nació la escuela realista, de inspiración positivista y de claros tintes nacionalistas. Pero antes de estudiarla, es necesario hacer referencia a un grupo de obras que trataron de denostar la obra de Colón, cali-

Fr. José Coll: Colón y La Rábida, Madrid: Imp. de A. Pérez Dubry 1891; citado por Luis Vidart: Colón y Bobadilla, Madrid: Rivadeneyra 1892, p. 37.

Joachim Heinrich Campe: Kolumbus oder die Entdekkung von Westindien, ein angenehmes und nüzliches Lesebuch für Kinder und junge Leute (1781); Alphonse de Lamartine: Christophe Colomb (1853); Washington Irving: A History of the life and voyages of Christopher Columbus (1828).

8 Marcelino Menéndez y Pelayo: „De los historiadores de Colón“, en: El Centenario, vol. II, Madrid 1892, p. 454. 
ficándolo de „infame, aventurero, usurpador, pirata traficante de carne humana" e introductor del nefasto catolicismo. No creo necesario aclarar que fueron escritas por protestantes y editadas principalmente en los Estados Unidos. El escritor Aaron Goodrich? escribió que

Desde la primera carta triunfal preparó el Almirante de las Indias la felicidad de los súbditos agregados a la corona de Castilla, anunciando que podrían sacarse de las islas cuantos esclavos se quisieran; inventó luego el canibalismo por remachar las cadenas; dio a luz las montañas de falsedades que para personas y cosas tenía oculta en el alma; descubrió la avaricia, la crueldad, inepcia, orgullo, insensatez que obligaron a desposeerle del mando $[\ldots]^{10}$

Baste esta cita para dar una breve muestra de la leyenda que en contra de Colón se desarrolló paralelamente a las leyendas religiosa e idealista. Todas ellas conformaron un Colón 'a la medida'.

\section{Del Centenario de Colón al Centenario del Descubrimiento}

El IV Centenario del avistamiento por Colón y sus marinos de la isla de Guanahaní, el 12 de octubre de 1492, se presentó ante el mundo finisecular como el Centenario de Colón. Así lo promovieron italianos y norteamericanos, y así llegó a la península ibérica, dando lugar a una violenta confrontación entre los partidarios de ensalzar y glorificar al gran navegante genovés, y los historiadores de la escuela realista, empeñados en aceptar sólo los datos biográficos colombinos que hubieran superado un minucioso análisis crítico a la luz de los documentos históricos.

El gran inspirador de esta escuela fue el marino Cesáreo Fernández Duro, autor de obras tan interesantes como Colón y Pinzón. Informe relativo a los pormenores del descubrimiento del Nuevo Mundo (Madrid 1883), Colón y la historia póstuma. Examen de la que escribió el Conde de Roselly de Lorgues (Madrid 1885), Nebulosa de Colón, según observaciones hechas en ambos mundos (Madrid 1890) y Pinzón en el descubrimiento de las Indias (Madrid 1892), amén de numerosos artículos, en los que analizó críticamente numerosos aspectos colombinos como los preparativos del viaje (etapa primitiva del Descubrimiento), la participación de Fernando el Católico y otros nobles de la corte en la génesis del proyecto colombino, las relaciones entre Colón y los Pinzones,

9 Aaron Goodrich: A History of the character and achievements of the so-called Christopher Columbus, New York: D. Appleton 1874.

10 Citado por Cesáreo Fernández Duro: Nebulosa de Colón, según observaciones hechas en ambos mundos, Madrid: Suc. de Rivadeneyra 1890, p. 59. etcétera. Con ello, se intentó reconstruir el contexto histórico en el que se desarrolló la empresa descubridora, algo así como descubrir cómo se produjo el Descubrimiento. ${ }^{11}$

Numerosas fueron las adhesiones que recibió Fernández Duro por parte de políticos y escritores en general: Marcelino Menéndez y Pelayo, Luis Vidart, Miguel Mir, Antonio Cánovas del Castillo, Juan Valera, Emilia Pardo Bazán, etcétera, quienes animaron a nuestro marino a poner en cuestionamiento el título del IV Centenario. En un trascendental artículo aparecido el verano de 1890 y titulado „Es el Centenario de Colón?“, Fernández Duro enumeró los objetivos de 1892:

España habrá de enaltecer entonces primero y ante todo a España, por aceptar la grande empresa, para lo cual las otras carecían de aptitud y arrojo; a los Reyes Católicos, representantes de su unidad, árbitros de la iniciación del viaje, a los monjes de la Rábida y los magnates que elevaron hasta las gradas del trono al extranjero de la capa raída, zaherido de loco; a los marineros de Palos que pusieron en sus naves vidas e intereses $[\ldots]^{12}$

y, como no, al gran Almirante.

En la nueva propuesta, descubrimiento y descubridor se separan. En adelante, la gloria del descubrimiento se hizo recaer en un ente histórico llamado España, convirtiéndose Colón en el instrumento de dicha empresa. El periodista Ángel Stor escribió:

No lo olvidemos en ocasión tan solemne. Hay en el descubrimiento de América un personaje más grande que Isabel y Fernando el Católico; más grande que Mendoza, Santangel, Deza, Marchena, Cabrero, Coloma y Pinzón; más grande que Colón mismo, porque no existe individuo que jamás sea capaz de lo que es capaz un pueblo. Este personaje es España, verdadera protagonista de aquella maravillosa epopeya, mirada como unipersonal por populares escritores americanos. ${ }^{13}$

De esta forma, durante las conmemoraciones del IV Centenario, simultáneamente a agrias polémicas entre los defensores de la imagen romántica de Colón y los partidarios de situar el descubrimiento físico de América en el contexto

"Salvador Bernabeu Albert: „Cesáreo Fernández Duro, Americanista“, en: Cuadernos del Instituto de Historia y Cultura Naval, nº 6, Madrid 1990, pp. 49-56.

12 Cesáreo Fernández Duro: „EEs el Centenario de Colón? Carta dirigida al Sr. D. Marcos Jiménez de la Espada, enumerando documentos apócrifos que se han publicado con referencia al Descubrimiento del Nuevo Mundo", en: Revista Contemporánea, vol. LXXIX, Madrid 1890, p. 130

13 Ángel Stor: „Las conferencias del Ateneo“, en: La Ilustración Española y Americana, vol. XXXIII, Madrid 1892, p. 147. 


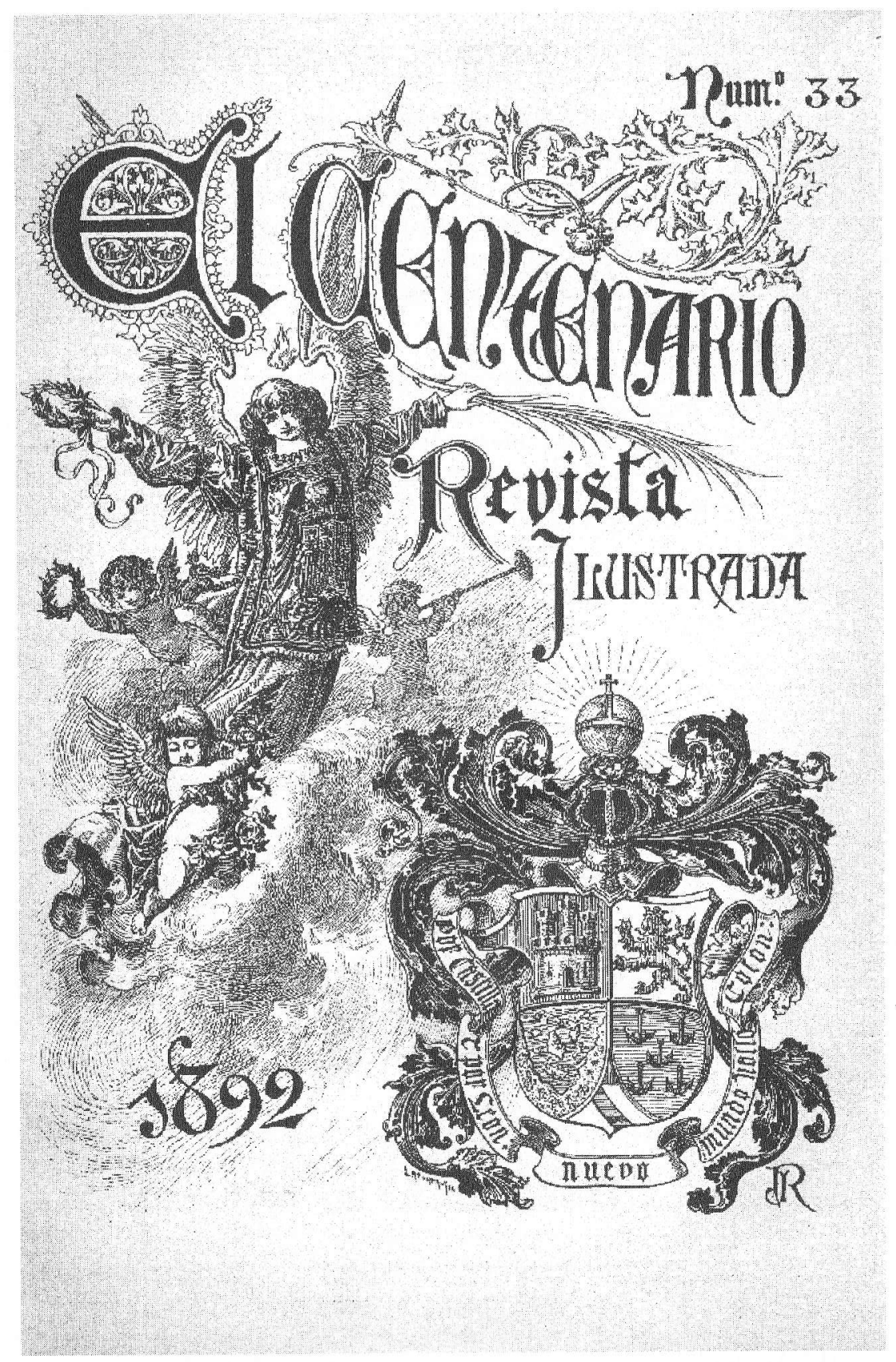

histórico-cultural que lo generó (la España de finales del siglo XV), se transformó el título y los contenidos del Centenario: el centenario de Colón se tornó en centenario del Descubrimiento de América.

Un motor fundamental de este cambio fue la rivalidad internacional (torneo honorífico) desatada entre Italia, España y los Estados Unidos. De hecho, la participación hispana en los proyectos centenarios estuvo motivada por el miedo a que el gran coloso del Norte, apoyado por las eficientes y coloristas comunidades italianas, acaparase la atención internacional en 1892 y aprovechase el Centenario para intensificar y consolidar las relaciones con las repúblicas iberoamericanas, objetivo que también compartían los gobiernos liberales y conservadores españoles de la recién instaurada monarquía.

La posición de España, evidentemente débil en comparación con los Estados Unidos, buscó relanzar sus lazos históricos y culturales con los países americanos y transformarlos en económicos y políticos. Una tarea ardua y costosa, pero apoyada en reiterados deseos de ciertos círculos hispanoamericanos de construir su identidad cultural en torno a los afectuosos brazos de la Madre Patria. Fue así como surgió una propuesta más ambiciosa y hábil que sirviese de guía para las conmemoraciones finiseculares. De aquí nació un tercer título para el IV Centenario: el Descubrimiento del Nuevo Mundo. Marcelino Menéndez y Pelayo, uno de los pensadores más importantes del siglo decimonónico español, dotó a esta propuesta de validez universal:

No es realmente el centenario de Colón lo que se celebra, sino el descubrimiento total del Nuevo Mundo, y aún si se quiere el conjunto de la grande obra colonial de castellanos y portugueses, ora se la haga arrancar de los descubrimientos y sublimes adivinaciones del Infante D. Enrique, ora, como otros quieren, de la primera ocupación de las islas Canarias. ${ }^{14}$

El descubrimiento del Nuevo Mundo, objetivo a conmemorar en 1892, título que recogía en su intimidad mayor riqueza temporal, espacial y cultural que las dos anteriores, fue la principal contribución de los pensadores del siglo XIX.

No obstante esta evolución en los títulos del IV Centenario, las polémicas que suscitó y los esfuerzos que fueron necesarios para que se gestasen y polarizasen las ideas de los pensadores en torno a los mismos, la mayoría de los españoles siguieron identificando las fiestas de 1892 con la figura del gran navegante genovés y con el resto de las personas que le ayudaron en su empresa, principalmente la reina Isabel la Católica. La revista Blanco y Negro incluyó en su

14 Marcelino Menéndez y Pelayo: „De los historiadores de Colón“, en: El Centenario, vol. II, Madrid 1892, p. 439. 


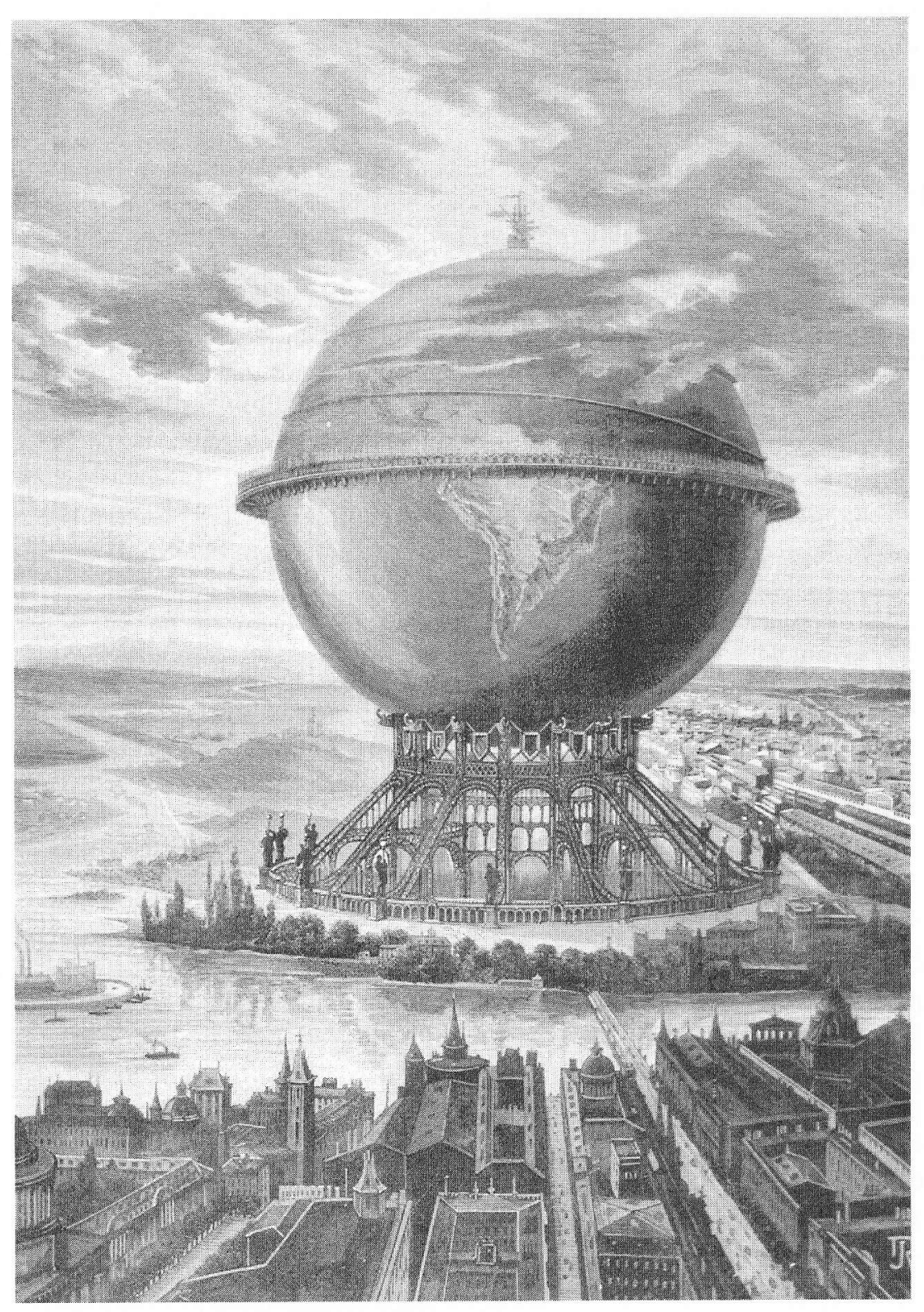

„Monumento colosal en memoria de Cristóbal Colón. Proyecto del arquitecto bilbaíno D. M. Alberto de Palacio." (Altura total del monumento: 400 metros) La Ilustración Española y Americana, No XXXII, 1890. número del 9 de octubre el siguiente artículo de Andrés Corzuelo titulado „Un poco de Colón“":

Ha de contar usted con que la industria no se duerme en las pajas y no se acerca usted a un escaparate donde no provoque su atención un artículo elaborado en honor del insigne genovés. Hay caramelos de Colón, bizcochos Colón, mazapán Colón y salchichón Colón, que es ya llevar las cosas a la exageración. No, es decir, yo no, los comerciantes son así. Ayer todo a Peral, hoy todo a Colón, mañana Dios dirá. Un industrial ha tenido una idea feliz. Ha fabricado unos bustos de Colón con chocolate y ha llenado el escaparate con este letrero: Colones a $0,50 .^{15}$

Evidentemente, los logros intelectuales deben pasar una larga cuarentena antes de ser incorporados a los acervos de un pueblo.

Por último, hay que hablar, aunque sea brevemente, de la polémica suscitada entre algunos escritores españoles e iberoamericanos. Juan Valera fue el principal defensor de la obra de España en América, que, como cabía esperar, quedó reducida a la defensa de la conquista y la colonización. Otros pensadores de reconocido prestigio en las jóvenes repúblicas no pudieron sustraerse a la oportunidad histórica de hacer oír sus voces. Emilio Castelar, por ejemplo, sentenció:

Por el descubrimiento aún pasan los americanos; pero no pasan por la conquista. Mas yo les pregunto: ¿que remedio nos queda, si de tal modo nos hizo la Naturaleza? Renegar de los conquistadores, porque guerrearon, equivaldría, en último término, a renegar de toda la estirpe humana y de toda la progenie nuestra, porque comenzó con el hombre prehistórico forzado por el medio ambiente suyo y por las imposiciones del fatalismo universal a una perpetua matanza. Somos hijos del sacrificador que inmolaba los prisioneros de guerra; hijos del caníbal que se nutría de carne humana; hijos del inquisidor que aventaba las cenizas de los herejes a cuatro puntos del aire. ${ }^{16}$

Como Castelar, otros notables escritores de la época salieron a la defensa del pasado español, tratando de demostrar que lo acontecido en la conquista fue violencia guerrera y no terror gratuito.

En definitiva, los españoles vieron transcurrir los meses de 1892 en medio de una batalla interna por los títulos del Centenario y una externa en defensa de la conquista y colonización. Los esfuerzos del gobierno español fueron evidentes en todos los terrenos, pero en el que pusieron más atención, el que polarizó las preeminentes mentes finiseculares - las relaciones con Hispanoamerica - no tuvo resultados tangibles, en parte por la lentitud de todo proceso diplomático

15 Andrés Corzuclo: „Un poco de Colón“, en: Blanco y Negro del 9 de octubre de 1892.

16 Salvador Bernabeu Albert: 1892. El IV Centenario del Descubrimiento de América en España: coyuntura y conmemoraciones, Madrid: CSIC 1987, pp. 129-130. 
y en parte por el impacto que produjo en la política y en el pensamiento español el desastre colonial de 1898.

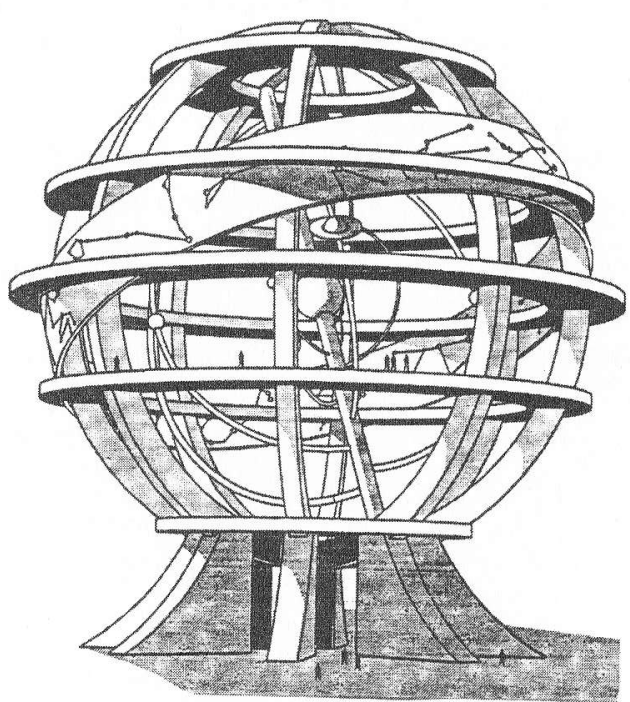

"Esfera armilar". Proyecto del escultor Rafael Trenor y el ingeniero José Antonio Fernández Ordoñez. Previsto erigir en Valdebernardo como 'símbolo de Madrid' y 'monumento emblemático del Quinto Centenario'. De una altura de 92 metros y el diámetro de la Tierra de 1.492 milímetros. (EL PAÍS, 3 de febrero de 1990)

\section{Nuevos títulos para un viejo Centenario}

Cien años después, un nuevo Centenario ha venido a turbar a los habitantes del planeta azul, a sus dirigentes y a sus instituciones. Pero ¿̇centenario de qué?, ¿quién nos convoca y qué debemos conmemorar? Cada época trae consigo una interpretación radical del hombre y - por extensión - de las relaciones entre los hombres y los pueblos. De la misma forma, los centenarios son espejos deformados donde queda reflejado el pensamiento de una determinada época. $Y$ hemos estudiado el acaecido en 1892, y al tratar de acercarme críticamente al de 1992 me sobrecogen las semejanzas con aquel, la fuerza que siguen teniendo sus propuestas y la terrible insolvencia de los debates y las polémicas. La primera característica del V Centenario es su antigüedad. Una antigüedad que tiñe los discursos, las paradas, los duelos hispanistas/indigenistas, el festival folklórico de turno y los utópicos planes de hermandad iberoamericana. Las flores que los presidentes van a depositar ante los múltiples monumentos a Colón el 12 de octubre son de plástico.

Nos quedan, sin embargo, los ecos de un nuevo debate en alguna parte del Nuevo Mundo. Si no supieramos del rigor científico de varios de sus protagonistas, me atrevería a afirmar que todo es un falso montaje de algún gobierno americano para no dejar estéril y sin su correspondiente lugar en las memorias oficiales los sucesos de 1992. Pero los contenidos de esos debates han enriquecido la pequeña historia de los centenarios de 1492 con nuevos títulos y propuestas. El V Centenario, desde mi punto de vista, se ha americanizado, como consecuencia de los oídos sordos de las grandes mentes europeas o las obsoletas propuestas de los gobiernos implicados.

Las dos novedades más importantes han sido la propuesta del reconocido indigenista mexicano Miguel León-Portilla, que ha dado pie a un interesante debate sobre el significado del Descubrimiento de América, y la novedad de las voces indianistas en el archivo de los discursos centenarios. León-Portilla ha propuesto el título de $V$ Centenario del Encuentro de Dos Mundos, asegurando reiteradamente que no se trata de un cambio gratuito, sino de darle un sentido distinto a la conmemoración, pues lo que sucedió en 1492 fue un encuentro de dos concepciones, de dos mundos geográficos, un encuentro de dos mundos humanos. El español y el indio se encontraron tanto desde el punto de vista físico como conceptual, iniciándose inmediatamente un proceso de fusión de dos tradiciones y dos razas, que logró anular la identificación orginaria de ambas. El título descubrimiento haría referencia exclusivo al punto de vista de los europeos, relegando las conceptuaciones indígenas. En consecuencia, la palabra descubrimiento es rechazada por eurocentrista, proponiéndose en cambio encuentro para resaltar la tradición cultural prehispánica. ¿Cómo vamos a celebrar a bombo y platillo ese descubrimiento que terminó con la conquista y sumisión de los pueblos indígenas?, se pregunta León-Portilla, para añadir, que la mayoría de los pueblos de Latinoamerica y del Tercer Mundo son mestizos, por lo que hay que respetar y resaltar sus valores y su herencia.

Tan interesante como la propuesta del famoso indigenista, ha sido el conjunto de críticas que ha provocado en su mismo país México. En primer lugar, los historiadores han censurado la falta de un debate sereno para juzgar y, en su caso, aprobar o rechazar el nuevo título, ya que el gobierno de Miguel de la Madrid confirmó oficialmente el cambio de Descubrimiento por el de Encuentro a golpe de decreto (18-IX-1986), sin contar con la comunidad de historiadores locales. El profesor Eduardo Blanquel señaló que la arrogancia de León-Portilla 
pone en tela de juicio la reputación científica de México y que el cambio responde exclusivamente a móviles políticos:

Como puede verse, la historia no se valida o se invalida por decreto, y su conocimiento y manejo implica un ejercicio libre de la inteligencia que no teme, sino al contrario, el examen y la confrontación de la verdad que alcanza. Además y como dijo alguien, 'es indigno de fe el historiador que intenta ocultar una página de la historia'. 17

Pero la crítica mas incisiva y sistemática ha sido la realizada por el prestigioso pensador Edmundo O'Gorman, autor de varios trabajos sobre la idea del Descubrimiento de América. Para este autor, el cambio de título del V Centenario era innecesario, ya que coinciden en el fondo con los ideales que inspiraron la celebración del Día de la Raza, esto es, reconocer, fomentar y exaltar los ideales y aspiraciones iberoamericanas. Además, el verdadero significado del 12 de octubre de 1492 no es ni descubrimiento ni encuentro, ya que lo que se produjo fue un proceso de invención desde la creencia de ser las tierras vistas parte de Asia hasta llegar a ser América. Pero lo que irrita a O'Gorman es la propuesta leonportillana de la existencia de dos mundos, uno viejo y otro nuevo, que se encuentran. Lo que ocurrió fue que Europa asumió la especifidad americana, integrándola como una parte más de la única cultura posible. Europa se apoderó de todo, reduciendo la realidad americana a la cultura occidental. Por tanto, el Encuentro de Dos Mundos es una falacia histórica, pues, de lo contrario, habría que suponer un encuentro per saecula saeculorum entre los dos mundos propuestos por León-Portilla. (ibid., p. 160)

Otras críticas al título del Encuentro han coincidido en censurar su excesiva politización, la crítica al colonialismo y al imperialismo que encierra y el convertirse en el abanderizador de los mestizos americanos, cuando una radicalidad en esos planteamientos podía terminar por escindir, de la gran familia hispana, a las regiones norteñas de México - de mayoría criolla - y a otras repúblicas de escasa presencia indígena. El doctor Ortega y Medina señala, en un brillante estudio sobre la idea colombina del descubrimiento en México, el peligro de olvidar el componente hispánico del mestizaje en favor del pasado indígena, así como el radicalismo antiespañol que se nota en la calle y en la prensa:

Por favorecer generosamente al internacionalismo tercermundista (pueblos africano $\mathrm{y}$ asiáticos) arriesgamos tal vez nuestra futura unanimidad iberoamericana en general y en particular la de nuestro México. (ibid., p. 155)

7 Juan Antonio Ortega y Medina: La idea colombina del Descubrimiento desde México (1836-1986), México: UNAM 1987, p. 159
Por último señalaré el desacuerdo del gran historiador Silvio Zavala, quien no encuentra suficientes fundamentos para desterrar de los libros y la escuela el término descubrimiento. ${ }^{18}$

El profesor Leopoldo Zea, director del Centro Coordinador y Difusor de Estudios Latinoamericanos (CCYDEL) de la UNAM, ha propuesto el título de encubrimiento para el V Centenario. El Descubrimiento sería para este famoso latinoamericanista simplemente un encubrimiento, pues los europeos que sucesivamente llegaron a América sólo vieron lo que querían ver, y sólo encontraron lo que quisieron encontrar. Esto es, la realidad americana fue enmascarada y modelada por los recién llegados de acuerdo a sus intereses y a sus concepciones. Colón creyó divisar las islas vecinas a la costa asiática; los representantes de la religión católica encubrieron a las religiones indígenas; los funcionarios coloniales encubrieron a los criollos y éstos, a su vez, a los mestizos e indios en nombre del progreso y la modernización. En consecuencia, el pasado latinoamericano sería para Zea una sucesión de encubrimientos, el primero y originario de los cuales sería el Descubrimiento. De ahí, la necesidad de descubrir lo encubierto para que América Latina encuentre su identidad, ya que todos esos encubrimientos han dado lugar a un género humano peculiar del que se habrá de partir en el futuro para evitar que nuevamente sea ocultado y que se logre una verdadera identidad del ser latinoamericano. El V Centenario es, pues, para Zea la oportunidad de reflexionar y desenmascarar los encubrimientos del pasado americano con el fin de avanzar hacia la creación de una región hispana, ibero o latinoamericana, „porque España e Hispanoamerica están obligadas a rebasar un pasado que debería ser ya definitivamente pasado“. ${ }^{19}$

Pero Zea apoya también la propuesta de León-Portilla de conmemorar el $V$ Centenario del Encuentro de Dos Mundos como un marco en el que se respetarían y se subrayarían las aportaciones de las culturas de ambos márgenes del Atlántico, aunque el encuentro por las tres carabelas de la bartera americana fue, más que un encuentro, un tropezón.

Las propuestas indígenas son las más novedosas y las más combativas dentro de las conmemoraciones del 12 de octubre de 1492. En primer lugar, porque su voz no se sintió en el Cuarto Centenario, pero principalmente porque las nuevas propuestas no han partido de los indigenistas 'de salón', sino de las propias comunidades indias: el indigenismo ha sido superado por el indianismo. Así, desde los 500 años de resistencia india, programa aprobado por la Confederación

18 Silvio Zavala: „Examen del título de la Conmemoración del V Centenario del Descubrimiento de América“, en: Mar Abierto, n 3, México 1985.

19 Ortega y Medina, op. cit., pp. 105-108 
de Nacionalidades Indígenas del Ecuador (CONAIDE), hasta la Campaña de autodescubrimiento de nuestra América, firmado por el Movimiento Indígena de Colombia, y sin olvidar el controvertido Día de la Dignidad del Indio, que coincide con la fecha clave del 12 de octubre, un espasmo de resentimiento y censura hacia la larga noche colonial y las injusticias contemporáneas ha recorrido la espina dorsal de América, naciendo un fuerte y ruidoso movimiento en contra de toda celebración del V Centenario, llámese este Descubrimiento o Encuentro. ${ }^{20}$

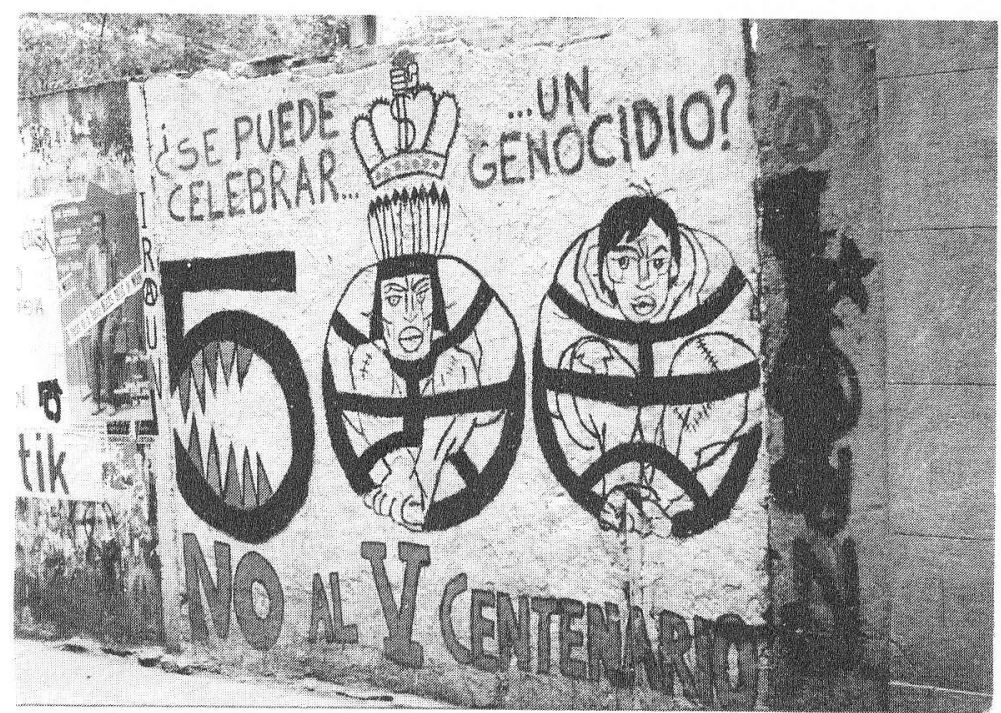

Mural en Bilbao, País Vasco

Sobre los objetivos del mismo, el guatemalteco Carlos Gómez señala que

Por boca de sus dirigentes más esclarecidos, se harán, en primer término, evocaciones de la desgracia que se abatió sobre sus pueblos y se expresará la condena de los hechos acaecidos en aquellos días aciagos. En segundo lugar, se enjuiciará con profundidad el proceso de colonización y su duración, partiendo de la base de que el mismo, en lo que a la población amerindia atañe, aún no ha terminado, toda vez que las mayorías indígenas siguen sufriendo la explotación económica, la discriminación

${ }^{20}$ [Varios:] Nuestra América frente al V Centenario. Emancipación e Identidad de América Latina (1492-1992), México: Joaquín Mortiz-Planeta 1989. Otros títulos semejantes se han publicado significativamente en Alemania y el País Vasco. racial, la segregación social y la falta de información, en el más amplio sentido de la palabra, es decir, la falta de acceso a una instrucción que ponga al servicio de las juventudes y de los sectores económicamente activos los conocimientos y las técnicas que son ya patrimonio de la humanidad y no de determinados países ni bloques de países. También se traerá a cuenta, para su revisión total, el problema de la tenencia de las tierras y las aguas, así como de los productos de las mismas, a efecto de redefinir territorios, así como zonas de laboreo y de explotación, bajo la base racional que nació con las civilizaciones agrarias de América y que el Occidente (después de haber perpetado el ecocidio) llama ahora ecología. ${ }^{21}$

Es, pues, un movimiento que no queda satisfecho con las autonomías que les regalan los estados-naciones actuales, sino que buscan una redefinición de fronteras con el fin de que las diversas naciones reales pasen a ser estados soberanos e independientes, borrándose así los límites heredados de los gobiernos coloniales. Es, por tanto, un movimiento que no nos es desconocido a los actuales europeos y que ha logrado levantar simpatías en numerosas personalidades y colectivos de todo el mundo; es más: para el propio movimiento indianista, los 500 años han sido todo un triunfo de consolidación de objetivos y de organización interamericana. El V Centenario se ha convertido en una inmensa bocina con la que exponer sus quejas y buscar simpatías en Europa para lograr apoyos en sus demandas transestatales. Los 500 años servirán - escribe el peruano Luis Guillermo Lumbreras - para

convertir la memoria del evento que dio origen al contacto, en acción de desarrollo de nuestra lucha por la liberación nacional y en reflexión explicativa de las condiciones actuales en nuestra existencia social, para diseñar un programa, un proyecto nacional que vuelva a convertir en indígena nuestra cultura todavía colonial y en libres y soberanos, nuevamente, a nuestros pueblos. ${ }^{22}$

En consecuencia, se quiere, a imitación de los frailes y gobernantes que trataron de encubrir las culturas indígenas, enterrar el pasado colonial y con ello la cultura mestiza que surgió del contacto entre siglos de la herencia española, india y negra.

${ }^{21}$ Carlos Gómez: „Los indios actuales de América frente al V Centenario“, en: Quinientos años de historia, sentido y proyección, México: FCE-Instituto Panamericano de Geografía e Historia 1991, p. 97.

22 Luis Guillermo Lumbreras: „La cultura indígena 500 años después“, en: Quinientos años de historia, sentido y proyección, México: FCE-Instituto Panamericano de Geografía e Historia 1991, p. 106. 


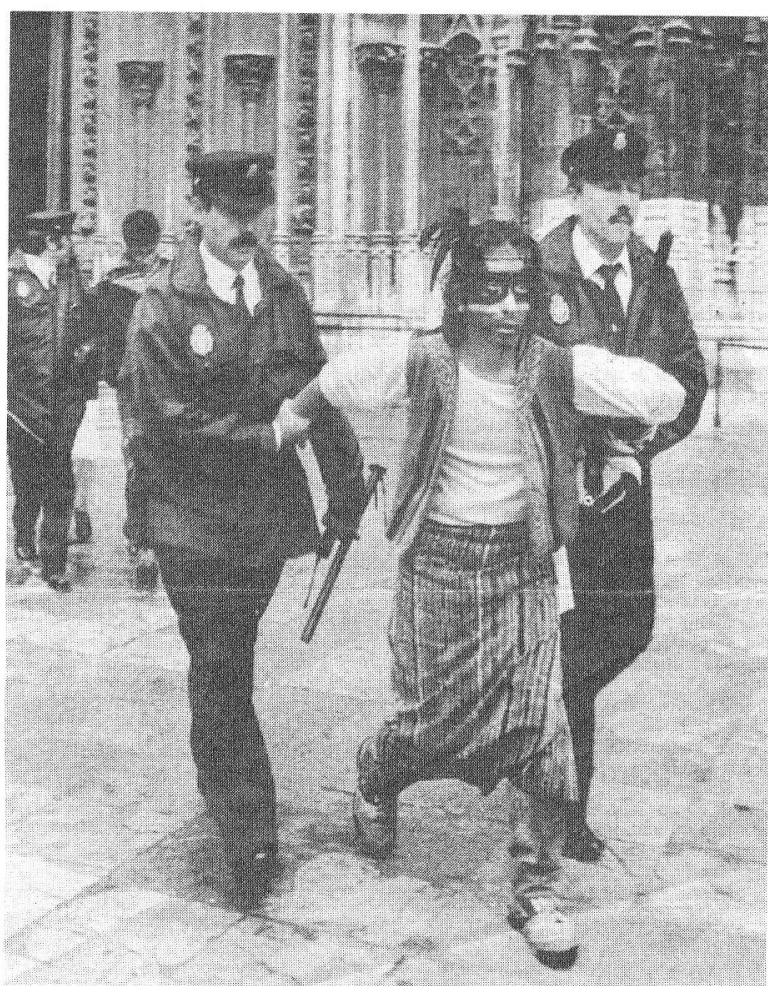

„La policía cargó ayer en el interior de la Catedral de Sevilla contra un grupo de manifestantes ataviados con ropajes indios que escenificaban el ritual de la muerte frente al sepúlcro de Cristóbal Colón." (EL PAÍS, Domingo 13 de octubre de 1991)

\section{Los Centenarios en el devenir histórico}

Cabe preguntarse sobre la importancia de los centenarios en el devenir histórico y cultural de un pueblo y si podemos acuñar la idea de los Centenarios del 12 de octubre de 1492 de la misma forma como se habla de la idea de América o de la idea de Europa. Se trataría de estudiar y reflexionar críticamente sobre los orígenes y avatares de las sucesivas interpretaciones que han aparecido en las diversas culturas sobre la llegada de Colón y sus hombres a la pequeña isla de Guanahaní. $^{23}$ Dejo esta tarea a otros pensadores más eruditos en la materia y me conformaré con exponer cinco características de todo centenario:

${ }^{23}$ Otros títulos como Desencubrimiento (Enrique Dussel), Evangelización de América (Juan Pablo II), Tropezón (Luis Cardoza y Aragón), 500 i Coños! (El Ahiuzotl. Jugosa Reseña de
1. Los centenarios son espejos de la sociedad que los conmemora, reflejándose en ellos las ideologías y mentalidades predominantes en ese momento. No es ocioso el pensar que, en consecuencia, todo centenario es interminable.

2. Los centenarios presentan a primera vista las deformaciones y mutilaciones inevitables que toda reducción de fenómenos complejos lleva consigo.

3. Junto a la vertiente histórico-cultural, los centenarios son presa ideal para los políticos y nacionalidades, que encuentran en ellos el marco más perfecto para difundir sus logros y miserias presentes y futuras.

4. Deben ser tan importantes para el historiador de los centenarios las presencias como las ausencias. Los silencios son a menudo una conmemoración.

5. Los centenarios nacieron con una finalidad pedagógica que se ha ido perdiendo a lo largo de su azarosa vida. Es, por tanto, fundamental el volver a recordar su acta de nacimiento: dar a conocer a todos los hombres los sucesos que cambiaron el transcurso de la Humanidad. Todos los centenarios son por ello universales y deben ser convertidos en una lección crítica sobre la historia de la humanidad.

Desde el Centenario de Colón al Centenario de la Invasión de América hemos recorrido cien años de ideas, discursos, monumentos, placas, flores, poemas...; mucho hay de obsoleto en todos ellos, pero la americanización actual del $\mathrm{V}$ Centenario nos permite albergar la esperanza de que no sea en vano y que se encuentra la lección crítica y justa que ofrecer a los organizadores del VI Centenario, en el 2092.
Encuentro de Dos Culturas con pelos, higados y señales), etcétera, enriquecen con nuevos matices el V Centenario, pero aportan poco a lo ya expuesto. 